\title{
ALGUNS CASOS, NEM NEURÓTICOS, NEM ABERTAMENTE PSICÓTICOS
}

Christian Hoffmann e Rosana Alves Costa

Christian Hoffmann
Psicanalista,
professor doutor
de Psicopatologia
Clínica, diretor da
Escola Doutoral
da Sorbonne Paris
Cité, Universidade
Paris Diderot e
pesquisador do
CRPMS.
Rosana Alves Costa
Doutora em
Psicologia Clínica
pela Universidade
Paris Descartes,
professora de
Psicologia Médica
do Departamento
de Psiquiatria
da Universidade
Federal de São
Paulo, psicóloga
do Centro de
Referência
da Infância e
Adolescência (Cria).

RESUMO: As subjetividades "nem neuróticas nem abertamente psicóticas" encontram um esclarecimento pela topologia que abre a uma clínica de borders na qual o limite se torna um caminho praticável do buraco (do vazio) na cura analítica. Este esclarecimento passa pela gênese do limite no inconsciente que se funde sobre uma experiência de perda do objeto primordial de satisfação, cujas resultantes são a faculdade de julgamento e o princípio de realidade. O "não limite" dessas subjetividades articula-se com a aceleração contemporânea do tempo entre o julgar e a ação.

Palavras-chave: Limite, borders e buracos no inconsciente, o vazio, a aceleração do tempo, subjetividades contemporâneas.

ABSTRACT: Some cases neither neurotics nor obviously psychotics. Subjectivities which are "neither neurotics nor obviously psychotics" are better explained at the light of typology that gives access to a clinic of borders where the border becomes a pathway to the hole (emptiness) in the analytical cure. Such explanation gets to the source of borders within the unconscious which originated in the early experience of the loss of the primordial object of satisfaction that gives birth to judgment faculty and to the reality principle. The "non-limit" of those types of subjectivity is related to the contemporary acceleration of laps of time that separates the judgment from the action.

Keywords: Limit, borders and holes within the unconscious, the emptiness, time acceleration, contemporary subjectivities. 
0 título deste trabalho é retirado de um texto de Freud de 1924, Neurose e psicose, que sempre será o tema desta questão clínica, do passado até hoje.

Para André Green (2012), o problema das estruturas não neuróticas, ontem e hoje, surge em indivíduos nos quais predomina uma fixação pré-genital e um Édipo negativo. Ele observa, com outros, a transformação que constitui o Homem dos Lobos na clínica freudiana e que abre para Green (2012) o estudo dos estados limites. Sabemos que a fixação pré-genital anal do Homem dos Lobos não lhe permitiu a escolha entre duas representações do ato sexual, ou seja, da vagina ou do ânus, o que resulta na clivagem do sujeito, acompanhada por uma disfunção do ego em sua capacidade de julgamento. Green lamenta a abordagem destas patologias pela destrutividade, o eu e as relações de objeto, que não reconhece a sexualidade e seu papel primordial e determinante, pela importância que toma a angústia de castração como uma bênção para a criança sair "dos problemas de angústia insustentáveis e sem saída vinculados à relação dual com a mãe" (GREEN, 2012, p.179).

Foi com Melanie Klein e Maurice Bouvet que as fixações pré-genitais se tornaram o ponto central da psicanálise, e foi sobre este terreno e por este motivo que surgiu o interesse pelo transtorno de personalidade limítrofe. Podemos recordar a via aberta por Stoller sobre o sexo e o gênero e, mais próximo de nós, Joyce Mac Dougall, que descreveu uma sexualidade contemporânea aditiva, explicando o efeito traumático de toda sexualidade, em que o conceito de castração já não é a referência. Deve-se reconhecer a André Green a percepção da insuficiência de tal explicação dos modos de gozos sexuais pela fixação traumática ou pré-genital. Ele propõe a utilização de outros mecanismos de defesa que não o recalque e avança no conceito freudiano de clivagem no qual Lacan introduz a foraclusão, como veremos mais adiante.

Recordemos da obra de Green o seguinte:

- A articulação da pulsão com a relação de objeto.

- As fixações pré-genitais e a perturbação da genitalidade.

- A relação de castração entre a angústia neurótica ou a angústia de separação borderline.

- A regressão pré-genital com seu correlato do desfuncionamento da capacidade de julgamento do eu.

- A transferência como meio de apreender a relação com o outro pela descoberta da "intimidade psíquica”, ou seja, a relação entre sexualidade e amor.

Uma observação sobre a transferência: para Green, diante de uma profunda angústia relacionada ao imago materno, existe uma transferência paterna possível neste tipo de patologia, quando o analista é investido de sentimentos contraditórios entre o chato e o protetor (BIRMAN \& HOFFMANN, 2014). 
O que se pode hoje em dia ainda esclarecer com Freud, no que diz respeito a estas patologias nem neuróticas e nem abertamente psicóticas?

Iniciaremos pelo estudo do julgamento. Em seu artigo La négation (1925/1985), Freud estudou pela primeira vez a maneira pela qual a função intelectual é gerada a partir da pulsão. O julgamento, e em especial a negação, permitem ao pensamento liberar-se dos limites do recalque e enriquecer-se de "conteúdos" indispensáveis para seu funcionamento. Em suma, o poder de julgamento (faculdade de julgar) abre o espaço psíquico para o pensamento.

O que é a função do julgamento? Ela deve resultar em duas decisões. Deve, em primeiro lugar, poder julgar o que é bom de introjetar para o eu-prazer e o que deve ser jogado fora, porque é ruim. Em seguida, deve julgar a existência real de uma coisa representada na realidade, isso por conta de um eu real que Freud chama de "prova da realidade" (idem, p.136-137); não se trata mais de saber se uma coisa, um objeto de satisfação, é boa para o eu-prazer, mas se ela existe no mundo exterior. Vemos bem que se trata de uma questão de interior e exterior, o que nos leva a questionar o limite e sua gênese no inconsciente. Temos uma primeira indicação de Freud, no final de seu texto, quando afirma que a condição da função do julgamento, e por consequência do princípio de realidade, é a realização da prévia perda do objeto que trouxe uma real satisfação.

Para resumir, a distinção entre um interior e um exterior se faz sobre a experiência de perda de um objeto de satisfação, que passa do eu-prazer seu mundo exterior (idem, p.138). A faculdade de julgar contribui para encontrar um objeto correspondente no mundo exterior. Vale lembrar, para os nossos propósitos, que "o julgar" decide sobre a passagem ao "ato".

A questão do limite (HOFFMANN, 2013) retorna/volta em O mal-estar da civilização (1929/2010), no qual Freud interroga sobre “sentimento de si”. É necessário partir da ideia de que a autonomia do ego é enganosa, ela se prolonga sem fronteiras no inconsciente pulsional, de que é apenas a fachada. Por outro lado, existe uma fronteira “clara e nítida” (idem, p.46) entre o eu e o mundo exterior, salvo nos casos patológicos. A gênese desta "fronteira” é tributária da experiência feita pelo bebê sobre o objeto de satisfação, como o seio, está “fora” de seu eu-prazer e seu reencontro necessita de uma ação específica. Esta oposição entre o eu-prazer e o objeto (perdido) empurra o eu ao reconhecimento do "mundo exterior" e, deste fato, ao reconhecimento dos limites do gozo do "ilimitado" (idem, p.49 e 56), de seu narcisismo de origem, como testemunha o "sentimento oceânico", "sensação de eternidade”. Assim, se instaura o princípio de realidade, pela faculdade de julgar entre o objeto perdido e o objeto correspondente no mundo exterior; experiência que, na maioria das vezes, resulta no julgamento de que “não é isso!” e de que nenhum objeto é capaz de proporcionar a satisfação pulsional - é daqui a falta que o sujeito experimenta pela satisfação. 
Podemos condensar nosso raciocínio/desenvolvimento da seguinte maneira. Na prática terapêutica, se quisermos encontrar a relação subjetiva de um sujeito com o limite, é necessário escutar suas "práticas de si” e tentar entender a presença, ou não, da experiência da falta.

Com Lacan, conseguimos precisar a relação do sujeito com a falta pela distinção de três modalidades da falta na subjetividade (SAFOUAN \& HOFFMANN, 2014).

A noção da falta não é uma inovação lacaniana, ela faz a substância mesma da pulsão freudiana. De fato, sabemos que, segundo Freud, a pulsão oral visa ao que ele chama de a primeira satisfação. Basta dizer que o objeto desta pulsão não é apenas o seio, mas o peito, como se fosse uma fonte de satisfação pela marca desse momento, segundo a expressão de Lacan. Em outras palavras, o seio funciona como a causa do desejo oral, desde que ele foi objeto de um desmame ou, mais precisamente, de um corte sofrido pelo sujeito como uma parte de si mesmo.

A perda deste objeto, que nenhum objeto comum nem nenhum dom saberiam/poderiam restaurar, permite-lhe funcionar como o guardião de um desejo que permanece como falta.

Ao nível anal, existe também a perda real de uma parte que se separa do corpo. Aos objetos anal e oral Lacan acrescenta a placenta, ou seja, este órgão, que medeia a relação entre a mãe e seu embrião, de modo que ele possa se alimentar e se desenvolver, faz parte dele, no sentido de ser constituído por seus próprios tecidos em vez dos da mãe.

Sabemos que a necessidade se articula em uma demanda. Mas, para além do que se articula na demanda como a falta, outra demanda aparece — a demanda de amor. Uma criança que está sendo cuidada, apenas de modo a responder às suas necessidades, sem palavras, sem sorriso e sem relações pessoais, encontra-se dentro da impossibilidade de se integrar em uma relação humana. Em outras palavras, é uma criança condenada a murchar.

No entanto, a demanda de amor induz a uma desvalorização de todo objeto que responde à demanda - este objeto torna-se um simples sinal de amor e não o próprio amor (amor dele mesmo). Nele, mesmo o amor permanece o que ele é, queremos dizer uma falta à qual responde adequadamente, uma falta comparável, e não o objeto; este, mais uma vez, é apenas um sinal.

A questão é: o que são a pulsão genital e o desejo sexual? Trata-se de saber por quais meios é introduzido um terceiro tipo de falta, diferente da necessidade de amor. Lacan responde pelo intermediário da metáfora paternal. Uma metáfora é uma substituição, cuja característica reside em que ela origina uma nova significação — cria um novo significado.

Admitimos que em virtude do fato da imaturidade marcar o ser humano no momento do nascimento, a experiência vivida com a mãe leva a criança à 
significação de uma relação de onipotência, da qual ela depende para sua sobrevivência. Precisamos, portanto, saber como se estrutura o desejo no momento em que a criança é, por assim dizer, surpreendida pela intrusão da sexualidade precoce. Remarcamos que esta aparição se desdobra da percepção de um desejo sexual da mãe, que aparecia até aqui como uma potência de dom ou de recusa de dom. Ou, então, basta pensar nos estragos neuróticos que engendra/origina em alguns uma determinada fantasia ou crença para assegurar, com seu pênis, não só o objeto, mas ainda a garantia de desejo do Outro, para que possamos avaliar a importância que retorna da significação de uma irredutibilidade da falta que em relação à mãe é da ordem do ter. Ou seja, o pênis não pode satisfazer o desejo da mãe.

A metáfora paternal substitui no inconsciente o nome do pai no desejo da mãe. A substituição deste significante, com carga simbólica portadora de interdição de incesto - ter um desejo que apareceria de outra maneira como um desejo que nada retém - engendra no sujeito um efeito de significação: é o phallus, tal qual ele aparece na Grécia antiga ao fim dos mistérios.

Aqui chegamos ao significado simbólico do nome do pai, desde que ele constitui não somente o significante do desejo da mãe, mas também o vínculo que une o desejo à interdição do gozo sexual da criança. É em função desta dimensão do nome do pai como ficção de linguagem que se aborda também a culpa que é inerente à gênese do desejo.

Após a identificação do limite a partir da perda e da existência de uma falta na construção subjetiva, interrogamos a prática possível do limite.

Em um belo texto sobre "margens, bordas, limites" (da singularidade), ${ }^{1}$ Jean Luc Nancy se interroga sobre o limite que limita e que singulariza o singular. Ele utiliza assim três noções: o limite, a borda e a margem. Em primeiro lugar, o limite é um fim, uma conclusão que não vem do exterior — é um fim que põe fim, como o final de uma história. Assim, ele é inerente ao singular enquanto seu "dentro" e ao mesmo tempo seu “fora”. Le limes latin designa o caminho e dá ao limite seu intervalo no qual podemos circular entre duas bordas. Portanto, se há uma ou duas bordas, vários cenários são possíveis. Em todo caso, esta questão se repete a cada apropriação de uma singularidade onde o limite faz borda, poderíamos dizer "faz corpo". Este trabalho de apropriação por um trabalho de pensamento de uma singularidade somente pode ser feito em um intervalo "fora de tempo-fora de lugar". Encontramos esta ideia em Agamben, ao definir a contemporaneidade pela "relação com seu próprio tempo, em que aderimos

\footnotetext{
${ }^{1}$ Esse texto foi apresentado no colóquio Rivages, organizado pela Prefeitura e Universidade de Nice, em julho de 2000.
} 
tudo tomando distância” (2008, p.22). Podemos pensar igualmente no caminho de Heidegger: A caminho da linguagem (1976).

Não estamos distante da costa e da margem, Mallarmé fala dos lábios como de "margens rosa". É interessante notar o que Jean-Pierre Vernant faz do mito de Actéon (1998), o herói da margem; ele compreende o mito como aquele da prova da passagem da adolescência à virilidade. Delacroix pintou a cena colocando Artémise sobre a outra margem de um estreito rio.

Podemos concluir com Jean-Luc Nancy (2000) que um mundo, uma singularidade, mantido na borda sem ver a outra borda é um mundo, ou uma singularidade, onde a margem está em ruína.

Voltemos agora à nossa questão sobre o tratamento analítico dos sujeitos borderline. Como disse Lacan (1955-56), nada parece mais com uma neurose do que uma pré-psicose (ou as if, como se); podemos dizer o mesmo de patologias limítrofes. O que nos motiva no tratamento, para além dos sinais clínicos indicados no DSM V e das questões clássicas da transferência, é quando o sujeito se aproxima do buraco de sua estrutura, no sentido de que ele é a borda de sua estrutura (idem, p.221) — o limite é a borda de sua estrutura - como disse Jean-Luc Nancy.

Tomemos simplesmente o clássico sentimento de vazio que geralmente testemunham estes sujeitos. Lacan evoca um caso que ele qualificava de "limite" (1986, p.140) em seu seminário sobre a ética da psicanálise, a propósito justamente de uma descrição clínica de um "espaço vazio" na subjetividade de uma paciente.

Este "vazio de existência”, como dizia um jovem adolescente, é um vazio muito diferente do que um sujeito neurótico pode experimentar, no sentido de que este último se agarrará à beira de uma esperança de um amanhã (melhor) que cante. Enfim, ele está em uma beira, vê o outro lado e o caminho a executar/percorrer, e isto o deprime, enquanto o sujeito borderline está à beira do precipício sem outra beira para se agarrar. Em termo de topologia lacaniana, eles estão, todos os dois, sobre um borde real com a diferença de que o sujeito neurótico tem à sua disposição uma beira (um horizonte) simbólico que pode se imaginarizar em todos os momentos (O fantasma).

A prática terapêutica com o sujeito borderline pode consistir em tentar dar borda ao buraco que se abre diante dele, procurando com ele o que Jean Oury ilustrava pela metáfora da "brasa em um monte de cinzas". Trata-se, assim, de encontrar no envelope simbólico do sujeito a existência de um ponto onde se detenha um pouco mais de tempo, onde exista um pouco de desejo e em consequência a falta, e soprar em cima com prudência para que a chama da vida retome com uma malha simbólica. Recordamos um jovem paciente, o qual, após várias tentativas sem sucesso, encontra certa nostalgia em um pequeno flerte, que se tornou o ponto de partida da construção de um desejo do outro, como no 
quadro de Actéon. Ao final da cura, ele quis confirmar que foram as metáforas que o ajudaram a se reconstruir um si.

Em termos da relação dessas patologias "sem limite” com nosso mundo contemporâneo, evocamos uma dessas características maiores de nossa atualidade, que é a aceleração vertiginosa do tempo, que expõe o sujeito (post-metafísico) à mania. Basta ler Paul Ricoeur (1985) e seu trabalho sobre tempos e narrativa para nos lembrarmos de que o trabalho de pensamento, a obra na narrativa está correlacionada à experiência temporal.

Recebido em 25/9/2014. Aceito em 6/10/2014.

\title{
REFERÊNCIAS
}

AGAMBEN, G. (2008) Qu'est ce que le contemporain? Paris: Rivages poche. BIRMAN, J. \& HOFFMANN, C. (2014) "Problématique du suivi psychothérapeutique de patients borderline”, in CHABOUDEZ, G. \& GILLIE, C. Actualités de la psychanalyse, Paris: Erès.

FREUD, S. (1924/1973) “Névrose et psychose”, in Névrose, psychose et perversion, Paris: PUF, p.286. . (1925/1985) “La négation”, in Résultats, idées, problèmes, Paris: PUF . (1929/2010) Le malaise dans la civilisation, Paris: Seuil.

GREEN, A. (2012) La clinique psychanalytique contemporaine, Paris: Ithaque. HEIDEGGER, M. (1976) Acheminement vers la parole, Paris: Gallimard.

HOFFMANN, C. (2013) Le concept de limite dans l'inconscient et ses états, Figures de la psychanalyse, n.25, Paris: Erès.

LACAN, J. (1955-56) Les psychoses, Paris: Seuil, p.216.

LACAN, J. (1986) L'éthique de la psychanalyse, Paris: Seuil, p.140.

RICOEUR, P. (1985) Temps et récit, T. 3, Paris: Seuil.

SAFOUAN, M. \& HOFFMANN, C. (2014) Questions psychanalytiques, Paris: Hermann.

VERNANT, J.-P. (1998) La mort dans les yeux, Paris: Hachette/Pluriel.

\author{
Christion Hoffmann \\ hoffmann.ch@wanadoo.fr \\ Rosana Alves Costa \\ rosanacostagarino@gmail.com
}


